\title{
Occurrence of European Rhinoceros Beetle, Oryctes nasicornis (L.) (Coleoptera: Scarabaeidae), in the Southern Highlands of Tanzania
}

\author{
Nicodemus D. Matojo \\ Department of Life Sciences, Mkwawa University College of Education, University of Dar es Salaam, Iringa, Tanzania \\ Email:ma tojodn@yahoo.com
}

How to cite this paper: Matojo, N.D. (2018) Occurrence of European Rhinoceros Beetle, Oryctes nasicornis (L.) (Coleoptera: Scarabaeidae), in the Southern Highlands of Tanzania. Advances in Entomology, 6, 9-13.

https://doi.org/10.4236/ae.2018.61002

Received: November 14, 2017

Accepted: December 25, 2017

Published: December 29, 2017

Copyright $\odot 2018$ by author and Scientific Research Publishing Inc. This work is licensed under the Creative Commons Attribution International License (CC BY 4.0).

http://creativecommons.org/licenses/by/4.0/

\begin{abstract}
The European rhinoceros beetle, Oryctes nasicornis (L.), is a large flying beetle in the subfamily Dynastinae of family Scarabaeidae and order Coleoptera. It is well-known to be a Palaearctic species, inhabiting Europe and Asia up to North Africa, with no reported material from the Sub-Saharan African region including Tanzania. The present work reports an occurrence of $O$. nasicornis in Tanzania specifically in Iringa region in the Southern Highlands zone of the country. The report is accompanied by description of the key morphological characters of the insect validating its diagnosis. The findings facilitate a basis for intervention of the existing records about $O$. nasicornis, including its biogeographical affiliation and the related undertakings. It is most likely that the species also ranges in other localities in Tanzania and the Sub-Saharan Africa region in general because of the existing proximity and interactions.
\end{abstract}

\section{Keywords \\ Coleoptera, Dynastinae, Oryctes nasicornis, Palaearctic Species, \\ Rhinoceros Beetle, Scarabaeidae}

\section{Introduction}

The rhinoceros beetles, which are also called the rhino beetles or horn beetles, belong to many genera in the subfamily Dynastinae of the family Scarabaeidae which also includes the dung beetles [1] [2] [3]. They are among the largest and strongest beetles in the world, reaching more than $150 \mathrm{~mm}$ (6 in) in length and able to lift up to 850 times their own body weight, but are completely harmless 
to humans because they cannot bite or sting [3] [4] [5]. Their common names refer to the characteristic horns borne on the top of the males of most species in the group resembling a rhinoceros; the horns can be as long as two-thirds the total body size and there can be other horns pointing forward from the centre of the thorax while the females are hornless [2] [4] [5]. The horns are used for dual purposes including digging underground and fighting other males for the right to mate [3] [4] [5]. In fact, the sexes of these insects are usually dimorphic (except Phileurini and some Cyclocephalini and Pentodontini) with males having either horns or enlarged tubercles or foretarsi [4] [5] [6]. The horn size generally provides a good indicator of the nutritional status and physical health of the beetle [6] [7]. The rhinoceros beetles also have rounded convex backs whose coloration varies from black to mottled greenish grey; some are shiny, almost metallic, whereas others may be covered with short fine hairs, giving them a velveteen appearance [5] [6] [8]. Many species of rhinoceros beetles are believed to originate in the rainforest and forest regions of central and southern America [1] [3] [6] [9].

The European rhinoceros beetle, Oryctes nasicornis (Linnaeus, 1758) is a large flying beetle which can reach up to $60 \mathrm{~mm}$, being one of the smallest species in the subfamily Dynastinae, but is still one of the largest and heaviest beetles found in Europe, and the only representative of this subfamily found in Northern Europe [2] [7] [10]. Males have a long curved horn on the head's front top (frons), while the females are hornless [5] [6] [7] [10]. The wing cases are dark brown with a glazed appearance, giving it the impression of a shiny conker; the legs and the underside of the body are covered with short red hair; the larvae live on dead, rotten wood and can thus be found in rotting wood stumps and in sawdust; taking around two years to develop in the larval stage, the adults emerge between March to May, flying around at dusk time in Europe; the adults do not feed and live up until the Autumn [6] [7] [8] [9] [10].

Oryctes nasicornis has nine synonyms: Oryctes pumilus Minck, 1916; Oryctes continuus Minck, 1914; Oryctes nasicornis subsp. progressiva Prell, 1914; Oryctes progressivus Prell, 1909; Oryctes nasutus Mulsant, 1842; Oryctes simus Mulsant, 1842; Oryctes tuberculatus Mulsant, 1842; Oryctus nasutus Mulsant, 1842; and Scarabaeus nasicornis Linnaeus, 1758 [6] [7] [8] [10]. The species is well-known to inhabit the Palaearctic region (excluding the British Isles), being widespread in the Mediterranean basin up to Pakistan, the Near East and North Africa [3] [4] [5] [6] [9] [10] with no reported material in the Sub-Saharan African region including Tanzania. Although found in a large number of countries, in some areas $O$. nasicornis is considered a rare species and has been given legal protection [5] [6] [7] [10]. The present work reports and describes $O$. nasicornis recently discovered in Tanzania.

\section{Materials and Methods}

The insect specimen under the present study was an adult beetle collected during rainy season in May 2017 on a rotting wood stump in a small bushy biotope near 
the eastern boundary of Mkwawa University College of Education (MUCE) campus, some $2 \mathrm{~km}$ north of the Iringa Municipal Headquarters in the Southern Highlands of Tanzania $\left(7^{\circ} 46^{\prime} 0^{\prime \prime S o u t h}, 35^{\circ} 42^{\prime} 0^{\prime \prime E a s t}\right)$. The specimen was preserved in $70 \%$ ethanol for morphological analysis. Species identification was done based on the morphological characters of the beetle particularly its external anatomy including the horns, head, thorax, elytra, hairs and related measurements whereby the body length was measured from the frons tip to the abdominal tip; the humeral width was measured as a distance between the extreme side margins of the shoulders [7] [9]. Taxonomic ranking of the specimen was donebased on published sources [2] [7] [9] [11].

\section{Results and Discussion}

\subsection{Referred Material (Figures 1-2)}

Holotype, adult, ( $\hat{\delta})$; Iringa Municipal (Southern Highlands); Tanzania, 7.46.0 ${ }^{\circ} \mathrm{S}, 35.42 .0^{\circ} \mathrm{E} ; 12$ May 2017; Oryctes nasicornis (Linnaeus, 1758) (Accepted name).

\subsection{Description}

The inferred insect is a male rhinoceros beetle with a rounded convex back. It is dark brown with a glazed (shinning) appearance and the apex of metatibia is strongly crenulate characteristic of the genus Oryctes [2] [7] [9] [11]. The legs and the underside of the body are covered with short red hair. The dorsum of thorax consists of a triangular scutellum. It is relatively small, measuring about $45 \mathrm{~mm}$ in body length (note that some other rhinoceros beetles measure up to $150 \mathrm{~mm}$ in body length) and humeral width of about $22 \mathrm{~mm}$ which is almost half the body length (Table 1). The elytra length is $30 \mathrm{~mm}$ hence two-thirds the body length and almost as long as the abdomen. The frons has a long medial rear-pointing horn which is relatively as long as the humeral width (i.e. $22 \mathrm{~mm}$ ) and almost half the body length, or three-quarters the elytra length. The pronotum has a pair of short fore-pointing horns of about $5 \mathrm{~mm}$ in length and radiating from the centre. Also

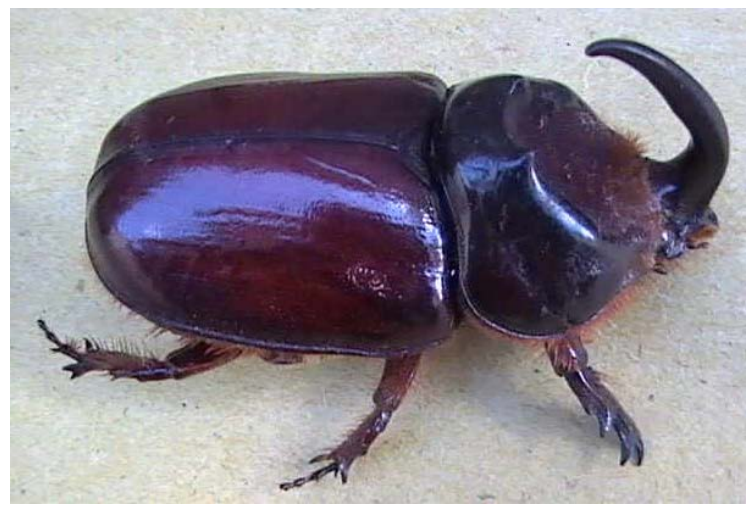

Figure 1. Oryctes nasicornis, Tanzania; side view. 


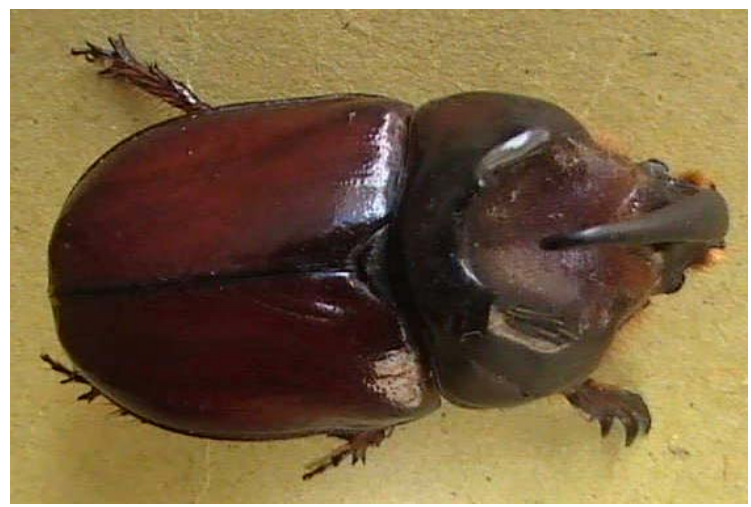

Figure 2. Oryctes nasicornis, Tanzania; dorsal view.

Table 1. Key morphometric measurements of $O$. nasicornis inhabiting Iringa region, Tanzania.

\begin{tabular}{ccc}
\hline Dimension & Measurement $(\mathrm{mm})$ & Ratio of Body Length \\
\hline Body length & 45 & 1.0 \\
Humeral width & 22 & 0.5 \\
Elytra length & 30 & 0.7 \\
Frons horn length & 22 & 0.5 \\
Pronotal horn length & 05 & 0.1 \\
Pronotal cavity diameter & 15 & 0.3 \\
\hline
\end{tabular}

the pronotum consists of a large deep fore cavity measuring about $15 \mathrm{~mm}$ in diameter which is almost one-third the body length, half the elytra length, or two-thirds the frons horn length.

\subsection{Diagnosis}

The insect is diagnosed as the European rhinoceros beetle, Oryctes nasicornis (L.), as identified by its unique long frons horn and other features described in Section 3.2 and supported by standard literature [2] [7] [9] [11]. It is a well-known species of the Palaearctic region, inhabiting Europe and Asia up to North Africa. It has never been reported from Tanzania or other Sub-Saharan African countries due to lack of supporting material. The species is evidently endemic in Tanzania as it has no capacity to fly over multiple thousands of kilometres from the Palearctic region where it is well-known to inhabit. The occurrence of the sample insect in Tanzania demonstrates the existence of its generation and thus its subpopulation in the country and probably other localities within Sub-Saharan Africa.

\section{Conclusion}

The present study has reported an occurrence of the European rhinoceros beetle, Oryctes nasicornis (L.) in Tanzania, illustrating for the first time that the species is not exclusively Palaearctic, but also ranges in Sub-Saharan Africa as exempli- 
fied by Tanzania. The findings facilitate a basis for intervention of the existing records and general understanding about $O$. nasicornis, including its biogeographical affiliation and related undertakings.

\section{Acknowledgements}

The author is highly indebted to the technical assistance of all members of the Life Sciences Department at Mkwawa University College of Education (MUCE), as well as the moral support of his family.

\section{Competing Interests}

Author has declared that no competing interests exist.

\section{References}

[1] Schoolmeesters, P. (2017) Scarabs: World Scarabaeidae Database (Version Jul 2017). In: Roskov, Y., Abucay, L., Orrell, T., Nicolson, D., Bailly, N., Kirk, P.M., Bourgoin, T., DeWalt, R.E., Decock, W., De Wever, A., van Nieukerken, E., Zarucchi, J. and Penev, L., Eds., Species 2000 \& ITIS Catalogue of Life, 30th October 2017. Species 2000: Naturalis, Leiden, The Netherlands. www.catalogueoflife.org/col

[2] Endrodi, S. (1985) The Dynastinae of the World. Dr. W. Junk Publisher, Dordrecht. $800 \mathrm{p}$.

[3] Bedford, G.O. (1980) Biology, Ecology and Control of Palm Rhinoceros Beetle. Annual Review of Entomology, 26, 213. https://doi.org/10.1146/annurev.en.25.010180.001521

[4] Sivakumar, T. and Mohan, C. (2013) Occurrence of Rhinoceros Beetle, Oryctes rhinoceros (L.), on Banana Cultivars in Kerala. Pest Management in Horticultural Ecosystems, 19, 99-101.

[5] Nair, C.P.R., Sukumaran, A.S., Murali and Mohan, C. (2002) Rhinoceros Beetle (Oryctes rhinoceros L.) and Its Biocontrol Agents. Technical Bulletin No. 43. Central Plantation Crops Research Institute, Kayamkulam.

[6] Rodger Kram (1996) Inexpensive Load Carrying By Rhinoceros Beetles. The Journal of Experimental Biology, 199, 609-612.

[7] Penev, L., Ed. (2017) Species Details: Oryctes nasicornis (Linnaeus, 1758). Species 2000 \& ITIS Catalogue of Life. http://www.catalogueoflife.org/col

[8] Mark, R.J. and Miller, K.B. (2012) Phylogeny and Systematics of the Giant Rhinoceros Beetles (Scarabaeidae: Dynastini). Insecta Mundi, 0263, 1-15.

[9] Ratcliffe, B.C. and Hardy, M. (2005) Collagenus dasysternus, a New Genus and Species of Dynastinae from Eastern Venezuela with a Key to the New World Genera of Pentodontini (Coleoptera: Scarabaeidae: Dynastinae). Coleopterists Bulletin, 59, 143-150. https://doi.org/10.1649/0010-065X(2005)059[0143:CDANGA]2.0.CO;2

[10] Krell, F.-T. (2002) On Nomenclature and Synonymy of Old World Dynastinae (Coleoptera, Scarabaeidae). Entomologische Blätter, 98, 37-46.

[11] Gasca-Álvarez, H.J. and Amat-García, G. (2010) Synopsis and Key to the Genera of Dynastinae (Coleoptera, Scarabaeoidea, Scarabaeidae) of Colombia. ZooKeys, 34, 153-192. 